\title{
Avaliação da postura de trabalhadores nas atividades de plantio e adubação em florestas plantadas
}

\author{
Janaine Vosniak ${ }^{1}$, Eduardo da Silva Lopes ${ }^{2}$, Mario Takao Inoue ${ }^{2}$, Adriano Batista ${ }^{3}$
}

\section{RESUMO}

Objetivou-se, com este trabalho, realizar uma avaliação das posturas adotadas pelos trabalhadores, nas atividades de plantio e adubação, em florestas plantadas, na região do Norte Pioneiro, Estado do Paraná. A avaliação das posturas foi realizada por meio de fotografias, filmagens e análise das cargas manuseadas pelos trabalhadores, sendo os dados, submetidos à análise no programa "Winowas" de análises de posturas. A população estudada foi composta por 13 trabalhadores, sendo seis no plantio e sete na adubação. Os resultados da atividade geral de plantio indicaram que as posturas adotadas foram prejudiciais à saúde dos trabalhadores e classificadas na Categoria 3, necessitando-se da adoção de melhorias com relação à ergonomia. Na atividade de adubação, as posturas foram classificadas na Categoria 1 e 3, sendo necessária a adoção de melhorias, com relação à ergonomia, em curto prazo. Em ambas as atividades, os trabalhadores permaneceram, a maior parte da jornada de trabalho, com as costas curvadas e manuseando cargas acima do limite estabelecido, situação prejudicial à saúde.

Palavras-chave: Postura, ergonomia, saúde no trabalho.

\begin{abstract}
Evaluation of working postures in workers at planting and fertilizing activities in forest plantations

The objective this research was to evaluate the occupational posture of workers in planting and fertilizing activities in forest plantations in the Norte Pioneiro Region, Paraná State. The workers were photographed and filmed during the performance of their activities and data were subjected to the WinOwas software of posture analysis. The studied population consisted of 13 forest workers, with six workers at manual planting and seven at manual fertilization. The results of posture analysis in the general planting activity indicated that some postures were considered harmful to workers' health and classified as category 3, requiring ergonomic actions as soon possible. The results for the fertilizing activity indicated postures classified as category 1 and 3, requiring ergonomic solutions in both the short and long term. In both activities, the workers remained most of the workday with their backs bent and handling loads above the recommended limit, which impairs health.
\end{abstract}

Key words: Ergonomics, occupational health, posture, .

\footnotetext{
Recebido para publicação em 17/06/2010 e aprovado em 02/09/2011

${ }^{1}$ Engenheira Florestal, MSc., Universidade Estadual do Centro-Oeste (UNICENTRO), PR 153, Km 7, 84.500-000, Riozinho, Irati, Paraná, Brasil. janainevosniak@ yahoo.com.br ${ }^{2}$ Engenheiro Florestal, Doutor, Departamento de Engenharia Florestal, Universidade Estadual do Centro-Oeste (UNICENTRO), PR 153, Km 7, 84.500-000, Irati, Paraná, Brasil. eslopes@pq.cnpq.br; martakino@gmail.com

${ }^{3}$ Especialista em Engenharia de Segurança do Trabalho, Instituto de Estudos Avançados e Pós Graduação (ESAP), Rua Novo Ateneu, 1.015, Vale do Jordão, 85.015-080, Guarapuava, Paraná, Brasil. adriano_batista_mec@yahoo.com.br
}

Rev. Ceres, Viçosa, v. 58, n.5, p. 584-592, set/out, 2011 


\section{INTRODUÇÃO}

Por causa da expansão do setor de florestas plantadas, no país, houve a necessidade da introdução de máquinas e equipamentos de alta tecnologia para o desenvolvimento de tarefas que eram realizadas de forma manual. Entretanto, tem-se observado uma demanda significativa por mão de obra, principalmente na etapa da implantação florestal, onde a maioria das atividades é realizada por métodos manuais e semimecanizados.

Além disso, as atividades são realizadas em ambientes abertos, onde, normalmente, os trabalhadores permanecem expostos a condições ambientais desfavoráveis, e com o uso contínuo de equipamentos e ferramentas que demandam elevado esforço físico e posturas inadequadas. Tal situação, segundo Iida (1995), pode causar desconforto, aumentar os riscos de acidentes e provocar danos à saúde dos trabalhadores, além de tornar susceptíveis o aparecimento de lesões por esforços repetitivos e doenças osteomusculares (LER/DORT) (LIMA et al., 2005).

Neste contexto, surge a ergonomia, que busca a melhoria das situações de conforto, segurança e saúde dos trabalhadores. Para Wisner (1999), a ergonomia é o conjunto de conhecimentos científicos relativos ao homem e necessários à concepção de instrumentos, máquinas e dispositivos que possam ser utilizados com o máximo de conforto, segurança e eficiência.

Dentro da análise ergonômica do trabalho, é importante a realização de estudos biomecânicos, por meio da análise da carga manuseada e das posturas adotadas pelos trabalhadores. Para Fiedler et al. (2003), as análises de posturas são úteis para a solução de problemas de queda de produtividade, danos à saúde dos trabalhadores e riscos de acidentes de trabalho, podendo ser corrigidas com a oferta de treinamentos específicos, permitindo aos trabalhadores a adoção de posturas seguras, saudáveis e confortáveis.

Fiedler et al. (2003) afirmam que no trabalho florestal, algumas das tarefas executadas são realizadas nas posições em pé, parada ou em movimento, e agachada, com a coluna torcida e com movimentos repetitivos, em que os trabalhadores podem assumir posturas incorretas durante a jornada de trabalho, causando problemas à saúde. Já Campos Santana (1996) diz que a posição parada e em pé é altamente fatigante, pois exige trabalho estático da musculatura envolvida para manter essa posição, em que, além da dificuldade de usar os próprios pés para o trabalho, frequentemente necessita-se do apoio das mãos e braços para manter a postura.

Entretanto, Silva (2001) afirma que a maior dificuldade em analisar e corrigir as posturas inadequadas está na identificação e no registro dessas posturas. Normalmen- te, as avaliações são realizadas de forma subjetiva e com base nas reclamações dos próprios trabalhadores, pelo que, muitas vezes, a solução surge quando o trabalhador já apresenta lesões lombares, com comprometimento de sua saúde.

Para representar o desempenho postural do ser humano no trabalho, existem diversos modelos de avaliação biomecânica, dentre os quais cita-se o método OWAS (Ovaco Working Posture Analysing System), que antecipa os riscos e sugere os pontos críticos em que deve ser realizada a reorganização ergonômica das atividades. Estes métodos produzem normas e recomendações para estabelecer limites posturais na realização do trabalho.

Portanto, considerando-se a importância da implantação florestal, que envolve grande contingente de trabalhadores e por causa da escassez de trabalhos nesta área, torna-se imprescindível observar e analisar as posturas assumidas pelos trabalhadores na execução do trabalho. Tal medida, segundo Alves (2001), possibilitará subsidiar a implementação de novas técnicas adaptadas à realidade ocupacional dos trabalhadores e promover melhorias em seu conforto, segurança e saúde.

Objetivou-se, com este trabalho, realizar uma avaliação das posturas típicas adotadas pelos trabalhadores em algumas atividades da implantação florestal, fornecendo subsídios para a reorganização do trabalho e melhorias das condições de conforto, saúde e segurança dos trabalhadores.

\section{MATERIAL E MÉTODOS}

O trabalho foi realizado em uma empresa prestadora de serviços florestais, localizada na Região do Norte Pioneiro, Estado do Paraná, nas coordenadas geográficas $24^{\circ} 01^{\prime} 58^{\prime \prime} \mathrm{S}$ e $50^{\circ} 27^{\prime} 28^{\prime \prime} \mathrm{W}$ e altitude de 776 metros (IBGE, 2008).

Conforme a classificação de Koeppen, o clima característico da região é Cfa, Subtropical Úmido Mesotérmico, com temperatura média anual de $21^{\circ} \mathrm{C}$ e precipitação média anual entre 1.200 e $1.400 \mathrm{~mm}$. O relevo da área estudada caracteriza-se como forte ondulado, com declividades entre 20 e $45 \%$.

Inicialmente, os trabalhadores participantes da pesquisa receberam esclarecimentos sobre a metodologia e os objetivos da pesquisa, por meio da leitura e assinatura do Termo de Consentimento Livre e Esclarecido (TCLE), em atendimento à Resolução No 196/96 da CONEP (Comissão Nacional de Ética em Pesquisa), do Ministério da Saúde.

A população pesquisada foi composta por uma amostra de seis trabalhadores que atuavam no plantio e sete na

Rev. Ceres, Viçosa, v. 58, n.5, p. 584-592, set/out, 2011 
adubação de plantios de Eucalyptus spp., selecionados aleatoriamente e avaliados individualmente. Os trabalhadores participantes eram do sexo masculino, com idade média de 31,3 anos, estatura média de 1,69 m, massa corporal de 72,2 kg e com média de 22,5 meses de experiência na função.

Foram realizadas 480 observações de posturas, totalizando 240 minutos diários de observação do trabalho para cada trabalhador e atividade estudados.

\section{Descrição das Atividades Estudadas}

O plantio consistia na inserção das mudas no terreno, executado pelo método manual com o uso de uma plantadora da empresa FRS. O conjunto possuía um peso total de $236,67 \mathrm{~N}$, sendo o peso da plantadora de $57,82 \mathrm{~N}$, o da bomba costal com hidrogel, de 151,41 N, e o da caixa com mudas, de $27,44 \mathrm{~N}$.

A adubação, realizada à época da coleta dos dados, era de arranque e de replantio, executado pelo método manual com uso de uma adubadora tipo "matraca" (Figura 2). O equipamento utilizado era da empresa FRS, com peso total de $202,86 \mathrm{~N}$, sendo o peso da adubadora de $42,14 \mathrm{~N}$, o da bomba costal, de $38,22 \mathrm{~N}$ e o do adubo, de $122,5 \mathrm{~N}$.

A Tabela 1 mostra as fases do ciclo de trabalho das atividades de plantio e de adubação.

\section{Coleta de Dados}

A análise das posturas típicas adotadas pelos trabalhadores na execução do trabalho foi realizada por meio de registros fotográficos, que possibilitaram a recomposição dos ciclos de trabalho; por meio de filmagens para a triagem das imagens e por meio de anotações, em campo, das posturas típicas adotadas, obtidas em intervalos de 30 segundos, com auxílio de um cronômetro centesimal.

Para a análise das posturas, foi utilizado o programa computacional OWAS, versão gratuita, sob domínio WinOWAS Copyright (C) 1996 Tampere University of Technology, Occupational Safety Engineering (WINOWAS, 1990). Com o recurso do programa, obteve-se a frequência de permanência dos trabalhadores nas diferentes posturas selecionadas.

De posse das imagens dos trabalhadores nas posturas típicas adotadas durante o trabalho, foi selecionado o código correspondente aos critérios considerados pelo método OWAS, que considera a posição da costa, dos membros superiores e inferiores e do peso da carga manuseada (Tabela 2). Em seguida, foi gerada, automaticamente, pelo programa, uma sequência de números, representando a análise do método OWAS. Ao final, o programa apresentou a análise postural, permitindo detectar os pontos críticos e classificando o esforço em categorias de ação, conforme mostrado na Tabela 3.

Tabela 1. Descrição técnica das fases das atividades estudadas durante o plantio e adubação de floresta de Eucaliptus spp

\begin{tabular}{|c|c|c|}
\hline \multirow{6}{*}{ Plantio } & Abastecimento da caixa de mudas & $\begin{array}{l}\text { Posicionamento do trabalhador próximo ao trator e abastecimento da caixa } \\
\text { de mudas. }\end{array}$ \\
\hline & Abastecimento de hidrogel & $\begin{array}{l}\text { Posicionamento do trabalhador próximo ao trator e abastecimento do } \\
\text { recipiente costal com hidrogel. }\end{array}$ \\
\hline & Deslocamento Cheio & $\begin{array}{l}\text { Deslocamento do trabalhador desde o ponto de abastecimento até a linha de } \\
\text { plantio, com o equipamento abastecido e apoiado nas costas. }\end{array}$ \\
\hline & Início do plantio & $\begin{array}{l}\text { Posicionamento do trabalhador em frente à cova e inserção da plantadeira } \\
\text { no solo. }\end{array}$ \\
\hline & Finalização do plantio & $\begin{array}{l}\text { Inserção da muda na plantadeira, encerrando com a retirada da plantadeira } \\
\text { do solo. }\end{array}$ \\
\hline & DeslocamentoVazio & $\begin{array}{l}\text { Deslocamento do trabalhador, a partir da linha de plantio até a chegada } \\
\text { próximo ao trator para o novo abastecimento. }\end{array}$ \\
\hline \multirow{6}{*}{ Adubação } & Abastecimento de adubo & $\begin{array}{l}\text { Posicionamento do trabalhador próximo ao trator e abastecimento do } \\
\text { recipiente costal com adubo. }\end{array}$ \\
\hline & Deslocamento Cheio & $\begin{array}{l}\text { Deslocamento do trabalhador desde o ponto de abastecimento até a linha de } \\
\text { mudas. }\end{array}$ \\
\hline & Início da adubação & $\begin{array}{l}\text { Posicionamento do trabalhador em frente à muda e inserção da adubadora } \\
\text { no solo. }\end{array}$ \\
\hline & Adubação propriamente dita & $\begin{array}{l}\text { Aplicação do adubo na muda, encerrando quando o trabalhador saía da linha } \\
\text { para retornar ao trator para novo abastecimento. }\end{array}$ \\
\hline & Deslocamento entre covas & Deslocamento do trabalhador com a adubadora entre mudas da linha adubada. \\
\hline & DeslocamentoVazio & $\begin{array}{l}\text { Deslocamento do trabalhador, a partir da linha de plantio até a chegada } \\
\text { próximo ao trator para o novo abastecimento. }\end{array}$ \\
\hline
\end{tabular}

Rev. Ceres, Viçosa, v. 58, n.5, p. 584-592, set/out, 2011 
Tabela 2. Composição dos códigos do método OWAS conforme a postura adotada

\begin{tabular}{ll}
\hline Critério & Códigos do método OWAS \\
\hline \multirow{2}{*}{ COSTA } & (1) reta \\
& (2) curvada \\
& (3) torcida ou com curso lateral em curva. \\
& (4) curvada e torcida ou curvada para frente e curso lateral. \\
\hline BRAÇOS & (1) os dois abaixo da altura dos ombros. \\
& (2) somente um dos braços erguido acima da altura dos ombros. \\
& (3) ambos os braços erguidos acima da altura dos ombros. \\
\hline PERNAS & (1) sentado, com as pernas abaixo da altura das nádegas. \\
& (2) em pé, com ambas as pernas esticadas. \\
& (3) em pé, com o peso em uma perna e a outra perna esticada. \\
& (5) em pé, ou agachado com um dos joelhos dobrados. \\
(6) ajoelhado com um ou ambos os joelhos. \\
(7) andando ou se movimentando. \\
\hline
\end{tabular}

Fonte: Adaptado do manual do Win OWAS (1990).

\section{RESULTADOS E DISCUSSÃO}

\section{Análise Geral das Posturas nas Atividades}

Os resultados obtidos pelo método OWAS são apresentados na Tabela 4. A classificação das posturas em categorias de ação possibilita o desenvolvimento de novos métodos de trabalho e a adoção de medidas preventivas, evitando, principalmente, o risco de lombalgias e problemas posturais futuros aos trabalhadores.

Como pode ser visto, a atividade de plantio foi classificada na categoria 3, indicando que, na maioria, as posturas adotadas pelos trabalhadores são prejudiciais à saúde, devendo ser tomadas medidas para sua correção o mais brevemente possível. É importante ressaltar que isso deveu-se, principalmente, ao posicionamento das costas, pois, em $78 \%$ das observações ao longo da jornada de trabalho, a coluna lombar dos trabalhadores apresentava-se curvada, enquanto o peso da carga manuseada estava acima de $196,0 \mathrm{~N}$, em $61 \%$ das observações. Silveira (2006), avaliando as posturas adotadas pelos trabalhadores nas atividades de coveamento e plantio manual, verificou que quase todas as articulações do corpo dos trabalhadores foram prejudicadas pelo excesso de carga manuseada no decorrer da execução do trabalho.

A atividade de adubação foi classificada nas categorias 1 e 3 . A categoria 1 indicou que as posturas adotadas pelos trabalhadores estavam normais, dispensando cuidados e não exigindo medidas corretivas. Já as posturas classificadas na categoria 3 indicaram serem prejudiciais à saúde, mostrando a necessidade de atenção em curto prazo e devendo ser alteradas o mais brevemente possível. A classifi- cação das posturas nas duas categorias ocorreu por causa dos diferentes valores de carga manuseados durante a execução da adubação, pois o trabalhador iniciava a atividade com o equipamento com peso médio de 201,88 N, que diminuía de peso no decorrer da aplicação, favorecendo a execução do trabalho e correção da postura.

É importante ressaltar que em $61 \%$ da jornada de trabalho, as costas dos trabalhadores estavam curvadas, enquanto, em $63 \%$, manuseavam uma carga com peso acima de 196,0 N. Essa situação foi considerada prejudicial à saúde, mostrando, assim, a necessidade de adoção de medidas ergonômicas para a melhoria das posturas dos trabalhadores na execução do trabalho. Dentre tais medidas, cita-se o estabelecimento de rodízio de funções entre eles, visando a eliminar o trabalho constante em pé, bem como o desenvolvimento de plantadora e adubadora, com regulagens, capazes de oferecer maior conforto aos trabalhadores de diferentes estaturas na execução do trabalho.

Tabela 3. Classificação das posturas do método OWAS

\begin{tabular}{ll}
\hline $\begin{array}{l}\text { Categoria } \\
\text { de Ação }\end{array}$ & Classe das posturas do método OWAS \\
\hline 1 & $\begin{array}{l}\text { Postura normal, não sendo exigida nenhuma } \\
\text { medida corretiva. }\end{array}$ \\
\hline 2 & $\begin{array}{l}\text { Postura que deve ser verificada na próxima } \\
\text { revisão dos métodos de trabalho. }\end{array}$ \\
\hline 3 & $\begin{array}{l}\text { Postura prejudicial, devendo ser tomadas } \\
\text { medidas para mudar a postura o mais breve } \\
\text { possível. }\end{array}$ \\
\hline 4 & $\begin{array}{l}\text { Postura extremamente prejudicial, devendo ser } \\
\text { tomadas medidas corretivas imediatamente. }\end{array}$ \\
\hline
\end{tabular}

Fonte: Kivi e Mattilla, 1991.

Rev. Ceres, Viçosa, v. 58, n.5, p. 584-592, set/out, 2011 


\section{Análise das Posturas nas Fases do Ciclo do Plantio}

As posturas típicas adotadas pelos trabalhadores em cada fase do ciclo do plantio, o código da fase e a classificação em categorias de ação são mostrados na Figura 3.

A fase de abastecimento de mudas apresentou os maiores riscos à saúde dos trabalhadores, por causa da posição das costas curvadas, que ocorria com grande frequência ao longo da jornada de trabalho. Em relação à posição das pernas, verificou-se que o peso do equipamento permanecia apoiado em apenas uma das pernas, enquanto a outra permanecia esticada. Essa situação pode ser prejudicial à saúde e à segurança dos trabalhadores, podendo ocasionar acidentes, principalmente quando o trabalho é executado em áreas de declividade acentuada e com resíduos da colheita de madeira, situação que prejudica o posicionamento dos trabalhadores para alcançarem as bandejas localizadas no fundo da carreta do trator.

Em relação à postura adotada pelos trabalhadores durante o abastecimento de hidrogel (Figura 1), verificase que o maior risco à saúde também ocorreu por causa da inclinação da coluna lombar. Considerando-se que a atividade de plantio é cíclica, essa postura se repetia com frequência ao longo da jornada de trabalho, podendo acarretar dores lombares. Para melhorar essa situação, recomenda-se a adoção de algumas medidas ergonômicas, como o desenvolvimento, pelo fabricante, de uma bomba costal com a abertura na parte superior, facilitando o abastecimento e evitando a inclinação das costas dos trabalhadores. Além disso, poderia ser desenvolvida uma plataforma para a acomodação do equipamento, durante a etapa de abastecimento.

Em relação à fase de deslocamento cheio, observouse que os trabalhadores deslocavam-se, do local de abastecimento até o interior do talhão, com o reservatório de hidrogel e caixa de mudas com peso médio de 236,67 N, ou seja, acima dos 196,0 $\mathrm{N}$ recomendados pelo programa como limite máximo. Apesar dessa situação, a classificação da postura foi considerada normal, não sendo necessária nenhuma medida corretiva, o que é explicado pela posição das costas dos trabalhadores, que estavam eretas e os braços abaixo dos ombros durante a fase de deslocamento.

$\mathrm{Na}$ fase inicial do plantio propriamente dito, os trabalhadores permaneciam com as costas curvadas, os dois braços abaixo do ombro, as pernas esticadas e manuseando uma carga com peso médio entre 98,0 e 196,0 N. Essa situação mostrou a necessidade de correção da postura, o mais brevemente possível, o que foi ocasionada, principalmente, pela posição das costas. Por outro lado, a finalização do plantio foi o momento de maior comprometimento à saúde dos trabalhadores, causado pela posição curvada da coluna lombar, agravada, principalmente nos

Tabela 4. Resultados do plantio e da adubação com o uso do método OWAS

\begin{tabular}{|c|c|c|c|c|c|}
\hline Atividade & Costas & Braços & Pernas & Carga & Resultado Final \\
\hline Plantio & $\begin{array}{l}78 \% \text { das } \\
\text { observações, a } \\
\text { coluna estava } \\
\text { curvada; } \\
6 \% \text { das observações, } \\
\text { a coluna estava } \\
\text { curvada e torcida; }\end{array}$ & $\begin{array}{l}\text { Estavam abaixo } \\
\text { dos ombros, em } \\
100 \% \text { das } \\
\text { observações; }\end{array}$ & $\begin{array}{l}63 \% \text { das observações, } \\
\text { estavam em pé e com as } \\
\text { pernas esticadas; } \\
6 \% \text { das observações, } \\
\text { estavam em pé, com o } \\
\text { peso em uma das pernas } \\
\text { e com a outra perna } \\
\text { esticada; } \\
\text { 32\% das observações, } \\
\text { deslocando-se; }\end{array}$ & $\begin{array}{l}39 \% \text { das } \\
\text { observações, } \\
\text { carga abaixo de } \\
10 \mathrm{~kg} ; \\
61 \% \text { das } \\
\text { observações, } \\
\text { carga acima de } \\
20 \mathrm{~kg} .\end{array}$ & $\begin{array}{l}\text { Categoria } 3, \\
\text { posturas } \\
\text { prejudiciais, } \\
\text { devem ser tomadas } \\
\text { medidas corretivas } \\
\text { o mais breve } \\
\text { possível (curto } \\
\text { prazo). }\end{array}$ \\
\hline Adubação & $\begin{array}{l}39 \% \text { das } \\
\text { observações, a } \\
\text { coluna estava reta; } \\
61 \% \text { das } \\
\text { observações, } \\
\text { curvada; }\end{array}$ & $\begin{array}{l}\text { Estavam abaixo } \\
\text { dos ombros, em } \\
100 \% \text { das } \\
\text { observações; }\end{array}$ & $\begin{array}{l}56 \% \text { das observações, } \\
\text { estavam na posição em } \\
\text { pé e com as pernas } \\
\text { esticadas; } \\
44 \% \text { das observações, } \\
\text { estavam se deslocando; }\end{array}$ & $\begin{array}{l}13 \% \text { das } \\
\text { observações, a } \\
\text { carga era menor } \\
\text { que } 10 \mathrm{~kg} ; \\
24 \% \text { das } \\
\text { observações, } \\
\text { carga entre } 10 \text { e } \\
20 \mathrm{~kg} \cdot \\
63 \% \text { das } \\
\text { observações, } \\
\text { carga acima de } \\
20 \mathrm{~kg} .\end{array}$ & $\begin{array}{l}\text { Categorias } 1 \text { e } 3 \text {. } \\
\text { Na categoria } 1 \text {, as } \\
\text { posturas são } \\
\text { normais, } \\
\text { dispensam } \\
\text { medidas } \\
\text { corretivas. Na } \\
\text { categoria } 3 \text {, as } \\
\text { posturas são } \\
\text { prejudiciais, } \\
\text { devem-se tomar } \\
\text { medidas corretivas } \\
\text { em breve. }\end{array}$ \\
\hline
\end{tabular}




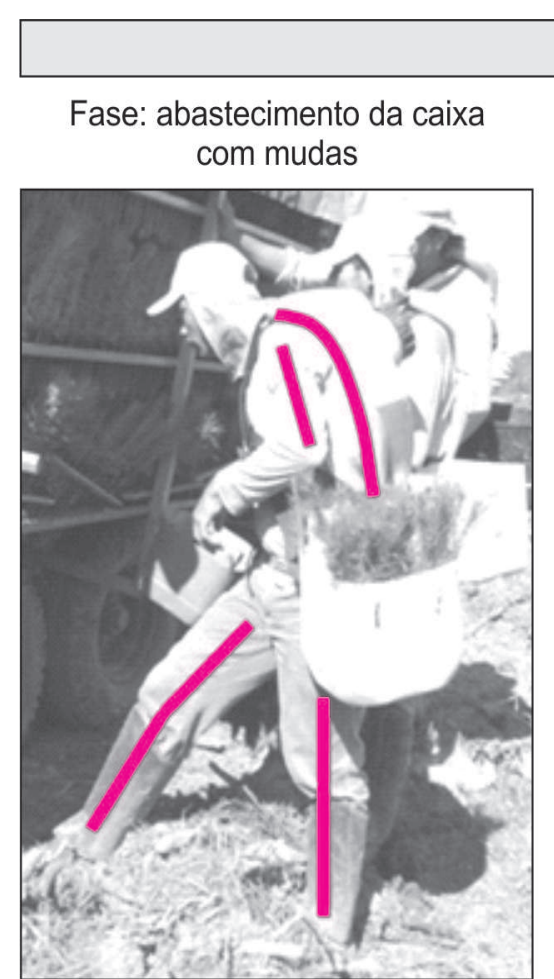

Código gerado pelo OWAS

\begin{tabular}{|c|c|c|c|c|}
\hline Costas & Braços & Pernas & $\begin{array}{c}\text { Carga/ } \\
\text { força }\end{array}$ & $\begin{array}{c}N^{\circ} \mathrm{da} \\
\text { fase }\end{array}$ \\
\hline 2 & 1 & 3 & 2 & 0.1 \\
\hline \multicolumn{4}{|c|}{ Classificação: Categoria 2} \\
\hline
\end{tabular}

Fase: Início do plantio propriamente dito

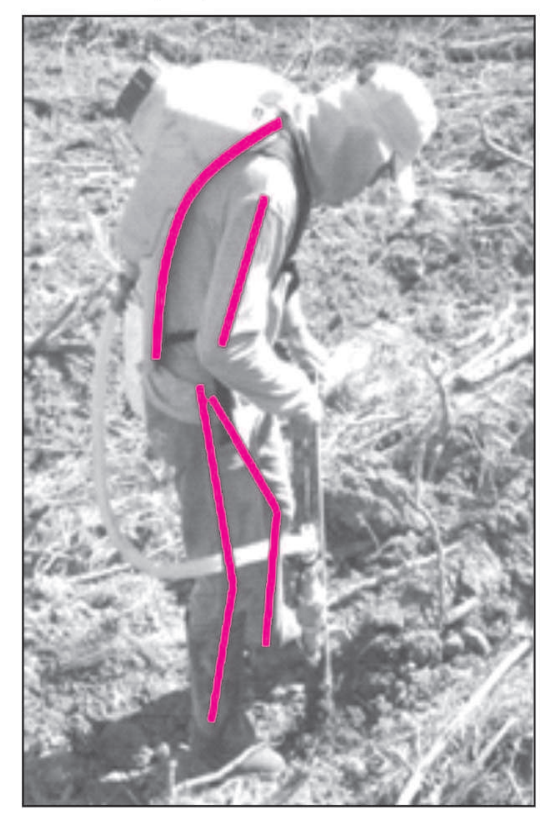

Código gerado pelo OWAS

\begin{tabular}{|c|c|c|c|c|}
\hline Costas & Braços & Pernas & $\begin{array}{c}\text { Carga// } \\
\text { força }\end{array}$ & $\begin{array}{c}\mathrm{N}^{0} \mathrm{da} \\
\text { fase }\end{array}$ \\
\hline 2 & 1 & 1 & 3 & 0.4 \\
\hline \multicolumn{4}{|c|}{ Classificação: Categoria 3} \\
\hline
\end{tabular}

Atividade: PLANTIO

Fase: abastecimento do recipiente com hidrogel

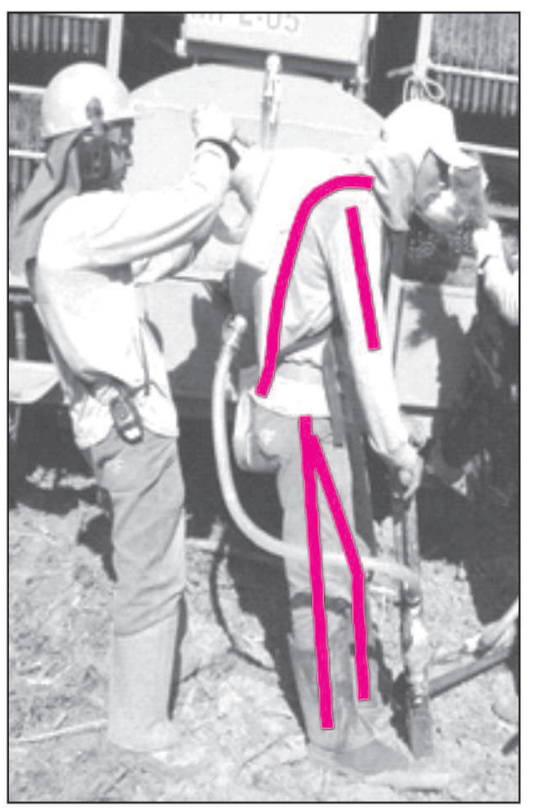

Código gerado pelo OWAS

\begin{tabular}{|c|c|c|c|c|}
\hline Costas & Braços & Pernas & $\begin{array}{c}\text { Carga/ } \\
\text { força }\end{array}$ & $\begin{array}{c}\mathrm{N}^{0} \mathrm{da} \\
\text { fase }\end{array}$ \\
\hline 2 & 1 & 2 & 2 & 0.2 \\
\hline \multicolumn{4}{|c|}{ Classificação: Categoria 2 } \\
\hline
\end{tabular}

Fase: Finalização do plantio propriamente dito

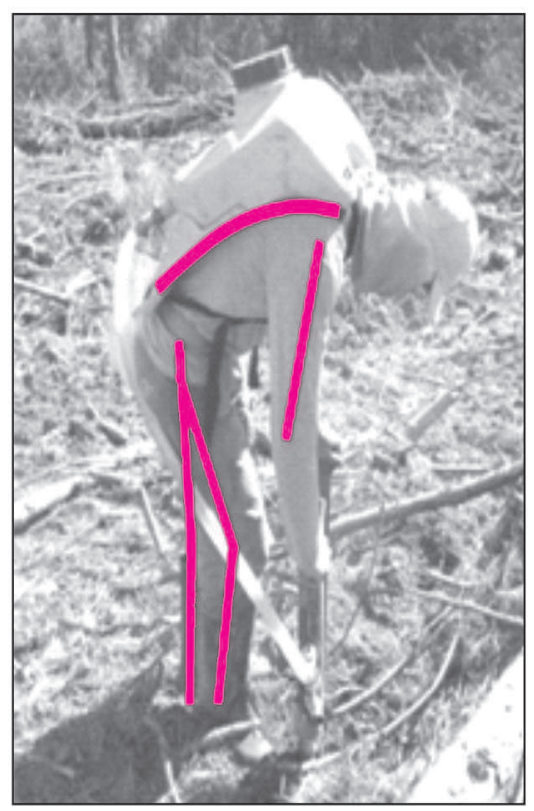

Código gerado pelo OWAS

\begin{tabular}{|c|c|c|c|c|}
\hline Costas & Braços & Pernas & $\begin{array}{c}\text { Carga/ } \\
\text { força }\end{array}$ & $\begin{array}{c}\mathrm{N}^{0} \mathrm{da} \\
\text { fase }\end{array}$ \\
\hline 2 & 1 & 1 & 3 & 0.5 \\
\hline \multicolumn{5}{|c|}{ Classificação: Categoria 3 } \\
\hline
\end{tabular}

Fase: deslocamento

com equipamento cheio

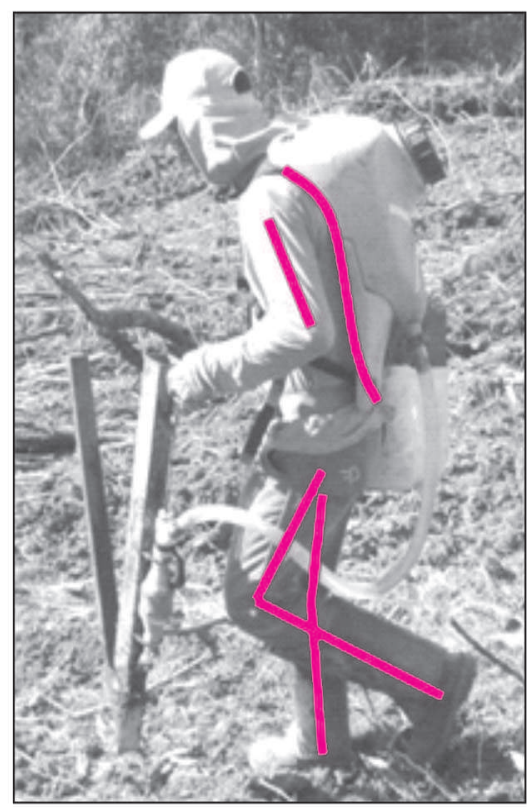

Código gerado pelo OWAS

\begin{tabular}{|c|c|c|c|c|}
\hline Costas & Braços & Pernas & $\begin{array}{c}\text { Carga/ } \\
\text { força }\end{array}$ & $\begin{array}{c}N^{\circ} \mathrm{da} \\
\text { fase }\end{array}$ \\
\hline 1 & 1 & 7 & 3 & 0.3 \\
\hline \multicolumn{4}{|c|}{ Classificação: Categoria 1} \\
\hline
\end{tabular}

Fase: Deslocamento com o equipamento vazio

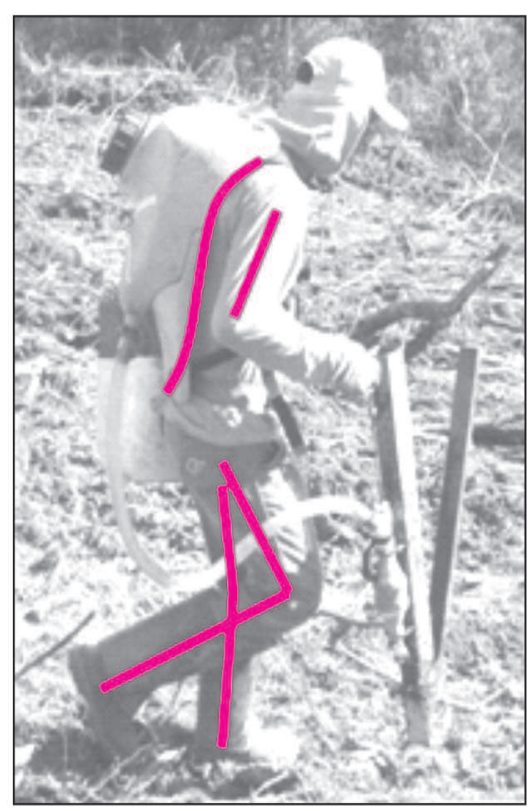

Código gerado pelo OWAS

\begin{tabular}{|c|c|c|c|c|}
\hline Costas & Braços & Pernas & $\begin{array}{c}\text { Carga/ } \\
\text { força }\end{array}$ & $\begin{array}{c}N^{0} \mathrm{da} \\
\text { fase }\end{array}$ \\
\hline 1 & 1 & 6 & 2 & 0.6 \\
\hline \multicolumn{4}{|c|}{ Classificação: Categoria 1} \\
\hline
\end{tabular}

Figura 1. Posturas típicas dos trabalhadores nas fases da atividade de plantio. 


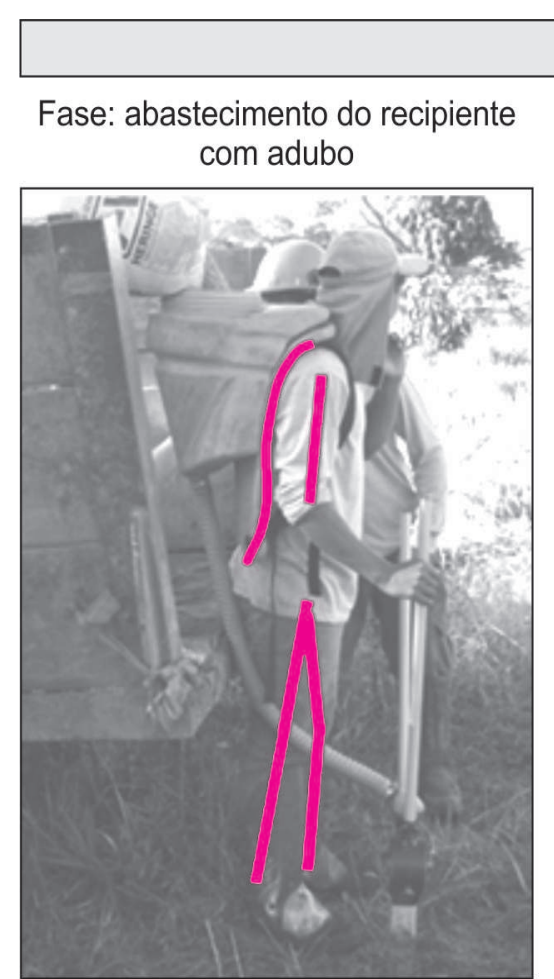

Código gerado pelo OWAS

\begin{tabular}{|c|c|c|c|c|}
\hline Costas & Braços & Pernas & $\begin{array}{c}\text { Carga/ } \\
\text { força }\end{array}$ & $\begin{array}{c}\mathrm{N}^{0} \mathrm{da} \\
\text { fase }\end{array}$ \\
\hline 1 & 1 & 1 & 2 & 1.1 \\
\hline \multicolumn{4}{|c|}{ Classificação: Categoria 1} \\
\hline
\end{tabular}

Fase: aplicação do adubo ao lado da cova

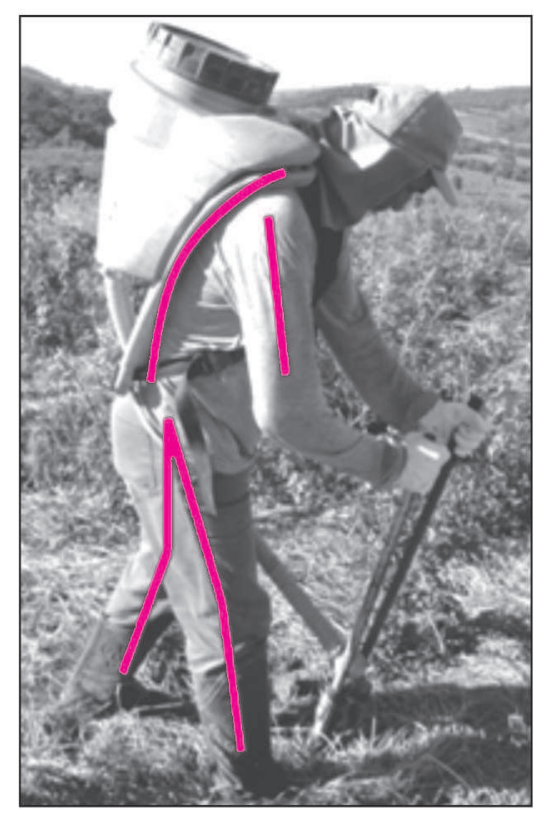

Código gerado pelo OWAS

\begin{tabular}{|c|c|c|c|c|}
\hline Costas & Braços & Pernas & $\begin{array}{c}\text { Carga// } \\
\text { força }\end{array}$ & $\begin{array}{c}N^{\circ} \mathrm{da} \\
\text { fase }\end{array}$ \\
\hline 2 & 1 & 2 & 2 & 1.4 \\
\hline \multicolumn{4}{|c|}{ Classificação: Categoria 2 } \\
\hline
\end{tabular}

\section{Atividade: ADUBAÇÃO}

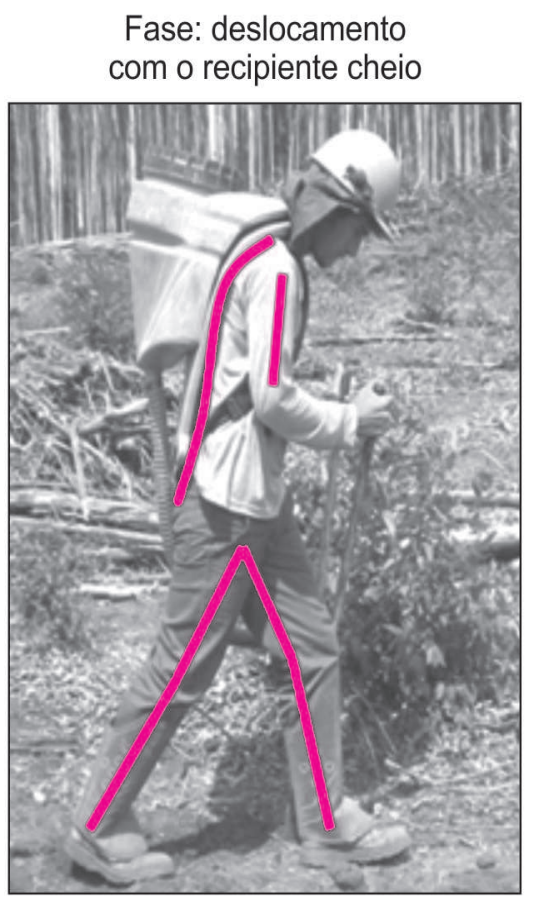

Código gerado pelo OWAS

\begin{tabular}{|c|c|c|c|c|}
\hline Costas & Braços & Pernas & $\begin{array}{c}\text { Cargal } \\
\text { força }\end{array}$ & $\begin{array}{c}N^{\circ} \mathrm{da} \\
\text { fase }\end{array}$ \\
\hline 2 & 1 & 6 & 3 & 1.2 \\
\hline \multicolumn{4}{|c|}{ Classificação: Categoria 3 } \\
\hline
\end{tabular}

Fase: deslocamento entre covas

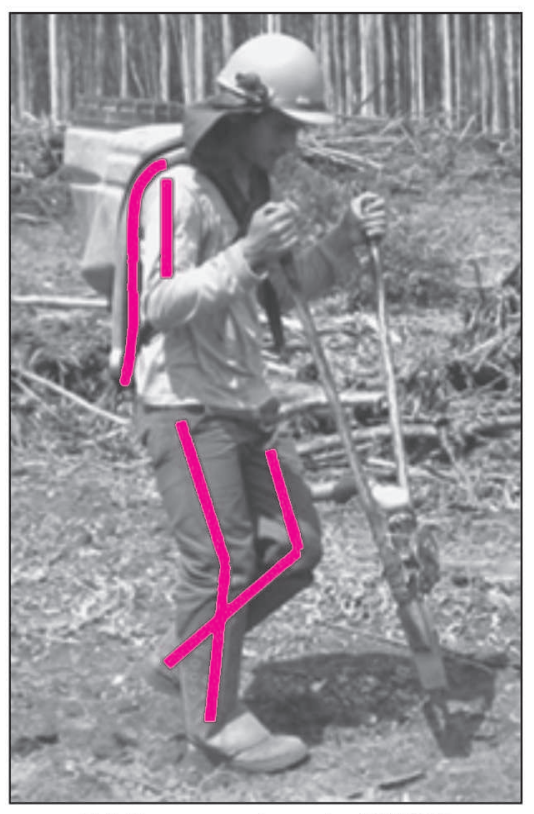

Código gerado pelo OWAS

\begin{tabular}{|c|c|c|c|c|}
\hline Costas & Braços & Pernas & $\begin{array}{c}\text { Carga/ } \\
\text { força }\end{array}$ & $\begin{array}{c}N^{\circ} \mathrm{da} \\
\text { fase }\end{array}$ \\
\hline 1 & 1 & 6 & 2 & 1.5 \\
\hline \multicolumn{4}{|c|}{ Classificação: Categoria 1} \\
\hline
\end{tabular}

Fase: início da aplicação de adubo

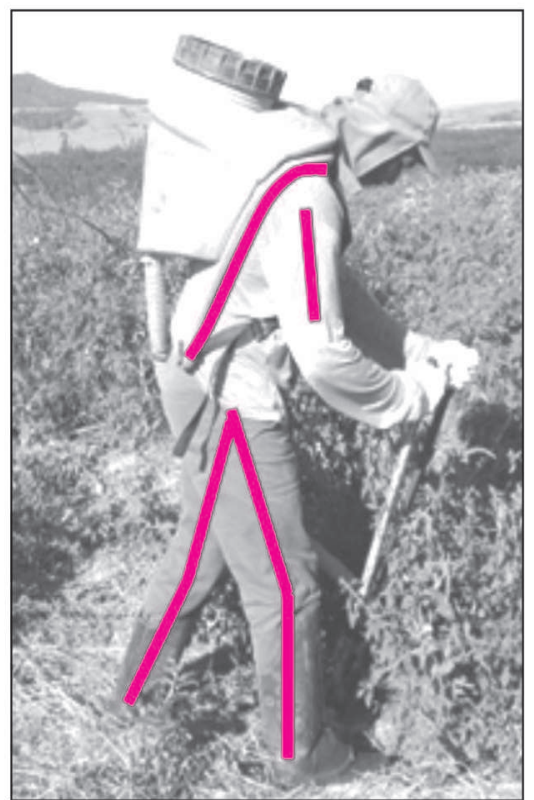

Código gerado pelo OWAS

\begin{tabular}{|c|c|c|c|c|}
\hline Costas & Braços & Pernas & $\begin{array}{c}\text { Carga/ } \\
\text { força }\end{array}$ & $\begin{array}{c}N^{\circ} \mathrm{da} \\
\text { fase }\end{array}$ \\
\hline 2 & 1 & 6 & 3 & 1.3 \\
\hline \multicolumn{4}{|c|}{ Classificação: Categoria 3 } \\
\hline
\end{tabular}

Fase: Deslocamento com o recipiente vazio

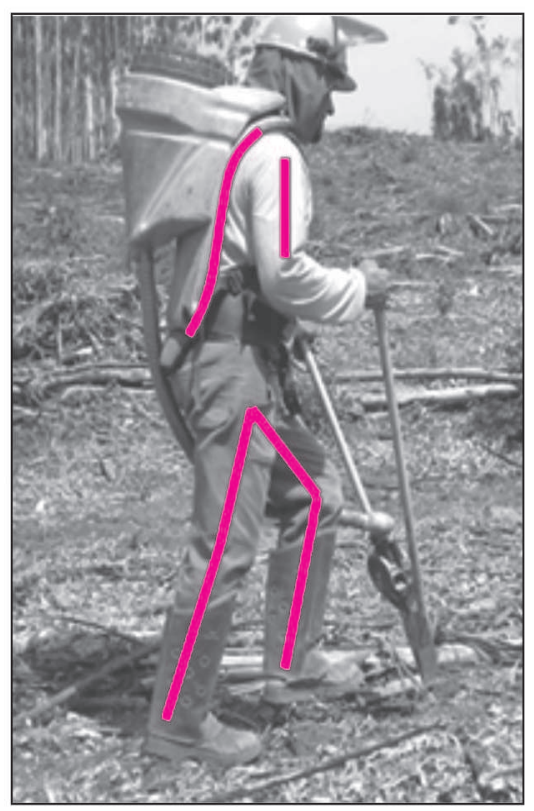

Código gerado pelo OWAS

Figura 2. Posturas típicas dos trabalhadores nas fases da atividade de adubação. 
trabalhadores de maior estatura, além da elevada força necessária para inserir a plantadeira no terreno para a abertura das covas. Esse resultado reforça a necessidade de melhorias nos projetos das plantadoras, com a instalação de regulagens que permitam o manuseio confortável pelos trabalhadores de diversas estaturas.

Já na fase de deslocamento com o equipamento vazio, a postura dos trabalhadores estava normal e sem a necessidade de medidas corretivas, o que é explicado principalmente pelo fato de as costas estarem eretas, os braços abaixo dos ombros, as pernas em movimento e manuseando uma carga com peso abaixo de 98,0 N.

\section{Análise das Posturas nas Fases do Ciclo da Adubação}

Na fase de abastecimento na atividade de adubação (Figura 2), a postura foi classificada na categoria 1, sendo considerada normal e dispensando a adoção de medidas corretivas. Portanto, o trabalhador poderá continuar adotando essa postura ao longo da jornada de trabalho, sem causar danos à sua saúde.

$\mathrm{Na}$ fase de deslocamento com o recipiente cheio de adubo, a postura foi classificada na categoria 3 , sendo considerada prejudicial à saúde e devendo ser melhorada o mais brevemente possível. $\mathrm{O}$ fator de maior risco foi influenciado pelo peso do recipiente de adubo $(202,86 \mathrm{~N}) \mathrm{e}$ pela longa distância percorrida pelo trabalhador, entre o ponto de abastecimento e a linha de plantio, chegando, em alguns casos, a 300 metros. Esse fato ocorreu, principalmente, em áreas de maior declividade, que dificultava o acesso do trator responsável pelo transporte do adubo e apoio às equipes de trabalhadores.

O resultado mostrou a necessidade de adoção de algumas medidas ergonômicas, como a redução da quantidade de adubo no recipiente, de forma a favorecer uma postura adequada dos trabalhadores. Além disso, tornase necessário o desenvolvimento de equipamentos alternativos, capazes de efetuar a distribuição do adubo nas áreas de difícil acesso, favorecendo o menor deslocamento dos trabalhadores.

Na fase de aplicação do adubo, a postura típica adotada pelos trabalhadores foi classificada na categoria 3, sendo prejudicial à saúde e devendo ser alterada com urgência. Tal situação desfavorável deveu-se à posição curvada das costas e ao peso do recipiente de adubo (202,86 N). Para melhorar as condições de trabalho, uma medida corretiva seria o desenvolvimento de regulagens na adubadora, permitindo o ajuste do equipamento às diferentes estaturas dos trabalhadores e condições do terreno.

Por fim, nas fases de deslocamento entre covas e deslocamento vazio, as posturas foram consideradas normais, dispensando cuidados e não sendo necessária a adoção de medidas corretivas.

\section{CONCLUSÕES}

O plantio foi considerado a atividade que exigiu as piores posturas, por causa do posicionamento das costas dos trabalhadores, que permaneceram curvadas na maior parte da jornada de trabalho.

$\mathrm{Na}$ atividade de adubação, os maiores riscos, advindos da adoção de posturas danosas, foram encontrados após o abastecimento da adubadora, por causa de a carga manuseada encontrar-se acima do limite estabelecido.

As articulações com maior nível de comprometimento à saúde do trabalhador durante a execução do trabalho foram as das costas, por causa das frequentes inclinações da coluna lombar.

Para a melhoria das posturas dos trabalhadores na execução das atividades, é necessário o estabelecimento de rodízios de funções entre eles, visando a eliminar o trabalho constante em pé, bem como o desenvolvimento de plantadora e adubadora com regulagens que ofereça maior conforto aos trabalhadores de diferentes estaturas.

\section{COMITÊ DE ÉTICA}

Esta pesquisa foi aprovada pelo Comitê de Ética da Universidade Estadual do Centro-Oeste, sob o protocolo número 14.556/2008, em 15/12/2008.

\section{AGRADECIMENTOS}

Ao Conselho Nacional de Desenvolvimento Científico e Tecnológico - CNPq, pelo apoio financeiro, e à Empresa Florestal pela cessão da área para realização do estudo.

\section{REFERÊNCIAS}

Alves, JU (2001) Avaliação ergonômica das atividades de propagação vegetativa de Eucalyptus spp em viveiros. Dissertação de Mestrado, Universidade Federal de Viçosa, Viçosa, 94 p.

Campos Santana, AM (1996) A abordagem ergonômica como proposta para melhoria do trabalho e produtividade em serviços de alimentação. Dissertação de Mestrado, Universidade Federal de Santa Catarina, Florianópolis, 215 p.

Fiedler, NC, Menezes, NS, Azevedo, INC \& Silva, JRM (2003) Avaliação biomecânica dos trabalhadores em marcenarias no distrito federal. Ciência Florestal, 13:99-109.

Instituto Brasileiro de Geografia e Estatística. Disponível em http:/ /www.ibge.gov.br. Acessado em: 20 jul 2008.

Iida, I (1995) Ergonomia: projeto e produção. São Paulo, Editora Edgard Blucher, 6. ${ }^{\mathrm{a}}$ ed.

Lima, JSS, Souza, AP, Machado, CC \& Oliveira, RB (2005) Avaliação de alguns fatores ergonômicos nos tratores "feller-buncher" e "skidder" utilizados na colheita de madeira. Revista Árvore, 29:291-298.

Silva, WG (2001) Análise ergonômica do posto de trabalho do armador de ferro da construção civil. Dissertação de Mestrado. Universidade Federal de Santa Catarina, Florianópolis, SC, 100 p. 
SILVEIRA, FSA (2006) Avaliação ergonômica da atividades de coveamento manual, coveamento semimecanizado, plantio manual e aplicação de corretivo no solo na implantação florestal de eucalipto. Dissertação de Mestrado, Centro Universitário de Caratinga, Caratinga, 85 p.

Win-Owas (1990) Manual software for OWAS analysis. Tampere University of Technology, Oc-cupational and Safety Engineering (1990). Disponível em: 〈http://turva.me.tut.fi/owas>. Acessado em: 21 de abril de 2008.

Wisner, A (1999) A inteligência no trabalho: textos selecionados de ergonomia. São Paulo: FUNDACENTRO, UNESP, 190 p. 